\title{
Materials and Their Characterization in the 21st Century
}

\author{
Mark Miodownik ${ }^{1,2}$ \\ 1. Institute of Making, University College London, London, United Kingdom. \\ 2. Mechanical Engineering Department, University College London, London, United Kingdom.
}

In this talk I look fifty years into the future of materials science to assess the needs for materials characterisation. Topics such as cities, energy, food and drink, and healthcare are explored in terms of their materials requirements and the requirements for microscopy and analysis. As the number of available materials increases, I assess the likelihood that the methodology of materials development itself might evolve. Will experiment combined with materials characterisation continue to dominate, or will approaches that combine big data and theory become more important forms of materials discovery?

Traditionally, approaches to materials selection and development were experimental and therefore slow. Much progress has been made, but it still takes decades to optimize suitable materials for a technological application. A principal reason for this long discovery process is that materials design is a complex, multidimensional optimization problem and the data needed to make informed choices usually do not exist. Theory blossomed in the 20th century, but its actual use in the invention of new materials in 2015 is still limited [2].

The US federal government's Materials Genome Initiative [2] recommends a change in methodology from a fragmented, experimentally based approach to a more integrated, theory- and data-led approach. This sounds appealing but this approach misses one very important issue, namely that there has been an increased specialization of materials practitioners, to the point where the scientists, technologists, and microscopists (i.e., the materials science community) involved in the development of new materials now move in both academic and social circles widely separated from those of industrial designers, architects, clothes makers, and medical experts (i.e., the materials arts community). It is the materials arts community who are experts in understanding the needs of society and therefore the materials requirements for future cities, energy, food and drink, and healthcare. In this talk I discuss ways to include the materials arts community into the development of new materials through a design-led methodology [3].

Materials are fundamentally multiscale, and there is as much to be learned about materials design through the production and trial of full-scale prototypes as through the application of theory. To assemble multidisciplinary teams with experts in each different scale requires laboratories that facilitate analysis, microscopy, and equipment to build and test physical prototypes. This will be a significant switch for materials scientists, who often hand over a material technology to the materials arts community and consider their work to be done [3].

There is much at stake, because materials have an immense cultural and environmental significance and the introduction of new materials by an isolated materials science community holds the prospect of a further deepening of the rift between scientists and society. Some combination of this materials arts approach and the materials genome approach is likely to be the hallmark of materials laboratories in the $21^{\text {st }}$ century [4]. 
References:

[1] A. Jain et al, APL Mater. 1 (2013), p. 011002.

[2] "Materials Genome Initiative Strategic Plan" (National Science and Technology Council, Washington, DC, 2014), available at https:/www.whitehouse.gov/sites/default/files/microsites/ ostp/NSTC/mgi_strategic_plan___dec_2014.pdf (accessed Feb 2016)

[3] M.A. Miodownik, MRS Bulletin 40 (2015), p, 1188.

[4] The author acknowledges funding from the EPSRC and the European Union's Seventh Framework Programme (FP7/2007-2013) under grant agreement no. 310311; the help of all members of the UCL Institute of Making for their help and technical support with this work; Ruby Wright for inspiration and the illustration.

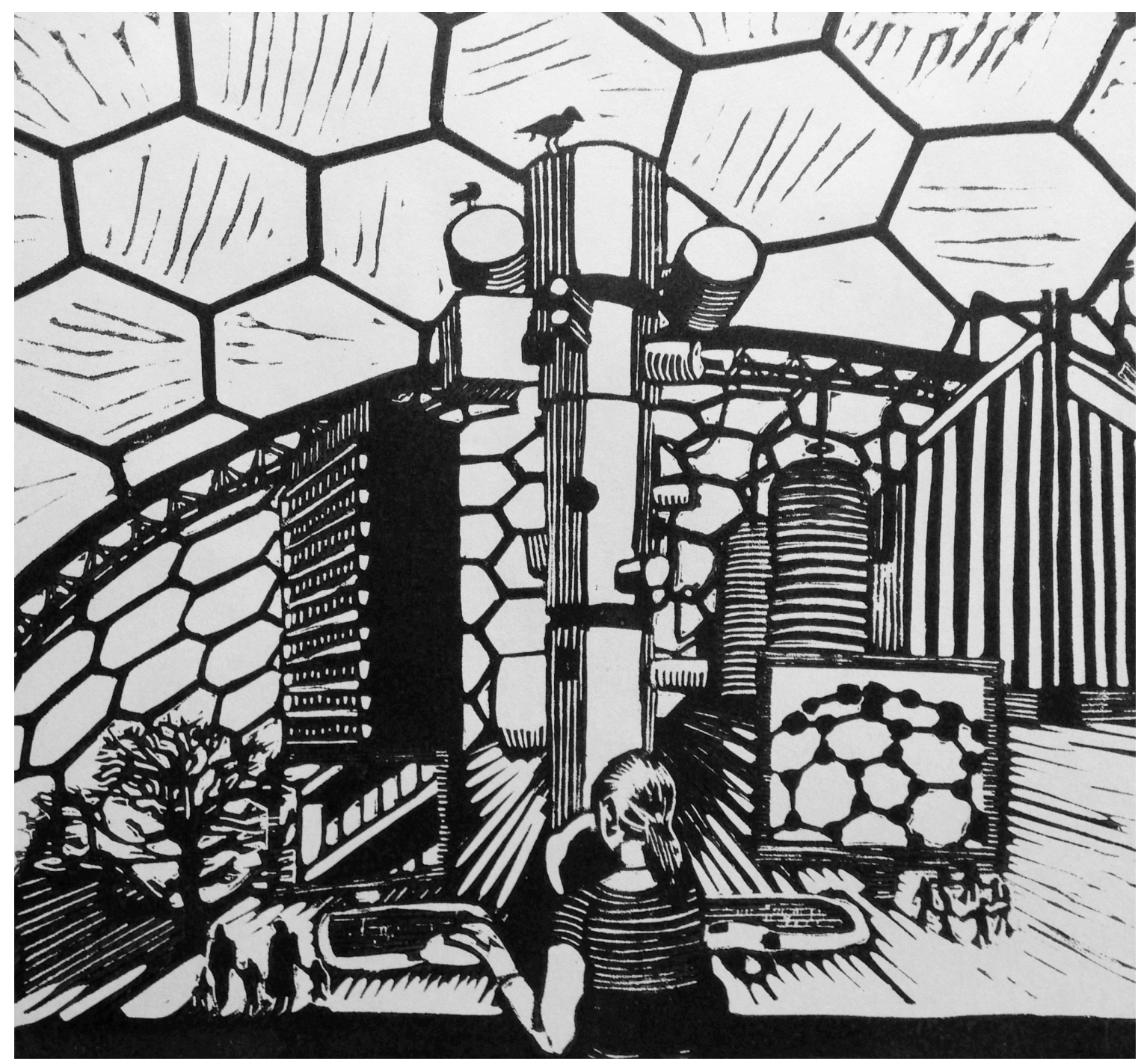

Figure 1. A possible future where buildings are designed using truly multiscale methods. 